\title{
EMA and FDA decisions based on flawed evidence to approve new cancer drugs negatively affect Latin American patients
}

\author{
Carlos E Durán doctoral student ${ }^{1}$, Martín Cañás associate professor ${ }^{2}$ coordinator $^{2}$, Thierry Christiaens \\ professor $^{1}$
}

${ }^{1}$ Heymans Institute for Pharmacology, Ghent University, 9000 Ghent, Belgium; ${ }^{2}$ Instituto de Ciencias de la Salud, Universidad Nacional Arturo Jauretche, Argentina; ${ }^{3}$ Pharmacology Area, Federación Médica de la Provincia de Buenos Aires, Argentina

\begin{abstract}
A recent editorial ${ }^{1}$ by Mintzes and colleagues warns about using flawed clinical trials to approve new cancer drugs in Europe ${ }^{2}$ and the US. ${ }^{3}$ The implications go further, however: during the past decade, several Latin American countries have adopted regulations that abbreviate the approval process of new drugs in the case of earlier approval by the European Medicines Agency (EMA) or the US Food and Drug Administration (FDA). Between 2012 and 2017 the Mexican regulator approved, through an accelerated procedure, 310 new drugs already authorised by the FDA, EMA, and Australian, Canadian, and Swiss regulators. ${ }^{4}$ In 2011 Ecuador launched a standardisation process of marketing authorisation. Current regulation establishes standardisation with the FDA, EMA, and several other national regulators. In 2016 Argentina authorised 15 new drugs through a similar process; only four showed some added therapeutic value. $^{5}$
\end{abstract}

Furthermore, the EMA and FDA implemented regulations to shorten the marketing authorisation process of certain drugs. Under these programmes, drugs are authorised on the basis of phase II trials, single arm trials, and surrogate end points. ${ }^{6}$ Consequently, whenever a drug is authorised by the EMA or FDA through an accelerated process, it can be quickly registered in several Latin American countries. Studies have shown that most cancer drugs that initially show positive results on surrogate outcomes later have disappointing results on overall survival..$^{73}$ Latin American regulators are seldom able to react, for example by revoking the authorisation when new evidence emerges. This leads to other problems that can result in financial risks to their healthcare systems, such as lawsuits and increased pressure to reimburse the drug or include it on public procurement lists.

We join the call to raise the bar for the approval of new cancer drugs. ${ }^{18}$ The EMA, FDA, and other international regulatory authorities must think globally to protect patients worldwide.

Competing interests: None declared.

Full response at: www.bmj.com/content/366/bmj.15399/rr-0.

1 Mintzes B, Vitry A. Flawed evidence underpins approval of new cancer drugs. BMJ 2019;366:I539910.1136/bmj.15399.

2 Naci H, Davis C, Savović J, et al. Design characteristics, risk of bias, and reporting of randomised controlled trials supporting approvals of cancer drugs by European Medicines Agency, 2014-16: cross sectional analysis. BMJ 2019;366:15221. 10.1136/bmj.15221 31533922

3 Gyawali B, Hey SP, Kesselheim AS. Assessment of the clinical benefit of cancer drugs receiving accelerated approval. JAMA Intern Med 2019;179:906-13. 10.1001/jamainternmed.2019.0462 31135808

4 Comisión Federal para la Protección contra Riesgos Sanitarios. Impulsa COFEPRIS la innovación farmacéutica. Comunicado de Prensa del Gobierno de México. 2018. www. gob.mx/cofepris/prensa/impulsa-cofepris-la-innovacion-farmaceutica.

5 Cañás M, Buschiazzo HO, Urtasun MA. Therapeutic value and price of the new pharmaceuticals commercialized in Argentina: Are they worth what they cost? Salud Colect 2019;15:e1962.31141093

6 Chen EY, Raghunathan V, Prasad V. An overview of cancer drugs approved by the US Food and Drug Administration based on the surrogate end point of response rate. JAMA Intern Med 2019;179:915-21. 10.1001/jamainternmed.2019.0583 31135822

7 Davis $\mathrm{C}, \mathrm{Naci} \mathrm{H}$, Gurpinar E, Poplavska E, Pinto A, Aggarwal A. Availability of evidence of benefits on overall survival and quality of life of cancer drugs approved by European Medicines Agency: retrospective cohort study of drug approvals 2009-13. BMJ 2017;359:j4530. 10.1136/bmj.j4530 28978555

8 Lehman R, Gross CP. An international perspective on drugs for cancer: the best of times, the worst of times. JAMA Intern Med 2019;179:913-4.

10.1001/jamainternmed.2019.0458 31135827

Published by the BMJ Publishing Group Limited. For permission to use (where not already granted under a licence) please go to http://group.bmj.com/group/rights-licensing/ permissions 